\title{
Dynamic analysis of railway bridges supported by a Winkler foundation under uniform partially distributed moving railway vehicles
}

\author{
J. A. Gbadeyan ${ }^{1}$ \& M. C. Agarana ${ }^{2}$ \\ ${ }^{I}$ Department of Mathematics, University of Ilorin, Nigeria \\ ${ }^{2}$ Department of Mathematics, College of Science and Technology, \\ Covenant University, Nigeria
}

\begin{abstract}
Transport structure such as railway bridges (plates), are subjected to moving railway vehicles (loads) which vary in both space and time. This branch of transport has experienced great advances, characterised by increasing high speed and weights of railway vehicles. Structures and media on which the railway vehicles move have, therefore, been subjected to vibration and dynamic stress more than ever before. The motivation for this paper is the observation that most of the works available in the literature are concerned with plates for which the effects of both rotatory inertia and shear deformation are neglected. Also the plates are assumed not resting on any foundation. In this paper, the dynamic response of railway track, modelled as an elastic rectangular plate, continuously supported by an elastic foundation and traversed by moving railway vehicle is investigated. Finite difference method is used to transform the set of coupled partial differential equations to a set of algebraic equations. The desired solutions are obtained with the aid of computer programs developed in conjunction with MATLAB. This shows that the elastic foundation, rotatory inertia and shear deformation have significant effect on the dynamic response of the railway bridge, to the moving railway vehicle (modelled as partially distributed moving load). In particular, it is observed that the deflection of the railway bridge decreases as the foundation moduli increase.

Keywords: Winkler foundation, Mindlin plate, finite difference method, dynamic response, railway vehicle, railway tracks.
\end{abstract}




\section{Introduction}

The moving load problem is a fundamental problem in several fields of Applied Mathematics, Mechanical Engineering, Applied Physics and Railway Engineering. The importance of these problems also manifested in numerous applications in the area of railway transportation. Rails and bridges are examples of structured elements to be designed to support moving masses. Furthermore, in connection with the design of machines processes, many members can be modelled as beams and plates acted upon by moving load. The challenges of these designs have attracted the attention of many investigations since 1897, when the Chester Rail Bridge collapsed in England [1]. Various kind of problems associated with moving loads have been presented in the excellent monograph by Fryba [2]. More recent development and results can be found in state-of-the-art review [3-5].

Also recently an attempt has been made to analyse the dynamic response of a Mindlin Elastic plate under the influence of moving load, without considering the possibility of the plate resting on any foundation [6]. Also another attempt, by Gbadeyan and Dada was to study the influence of elastic foundation on the plate under a moving load, but without considering the influence of rotatory inertia and shear deformation on the plate [7].

In the present work, the model suggested in reference $[6,7]$ is extended to include the effect of foundation reaction on the vibration of Mindlin plate. The foundation reaction is modelled as Winkler type. An attempt is therefore made in this paper to carry out a dynamic analysis of reactions of railway track, as an elastic structure, on elastic foundation under the influence of an external moving load - railway vehicle.

\section{Problem definition}

A railway bridge, modelled as a rectangular plate, with a moving railway vehicle (moving load) and different boundary conditions is considered. The load is relatively large, that is, its inertia cannot be neglected, and is moving along the mid-space on the surface of the plate, supported by a Winkler foundation, as shown in figure 1 .

\subsection{Assumptions}

(i) The plate is of constant cross-section; (ii) the moving load moves with a constant speed; (iii) The moving load is guided in such a way that it keeps contact with the plate throughout the motion; (iv) The plate is continuously supported by a Winkler foundation; (v) The moving load is partially distributed; (vi) The rectangular Mindlin plate is elastic; (vii) No damping in the system; (viii) Uniform gravitational field and (ix) Constant mass $\left(\mathrm{M}_{\mathrm{L}}\right)$ of the load on the plate. 


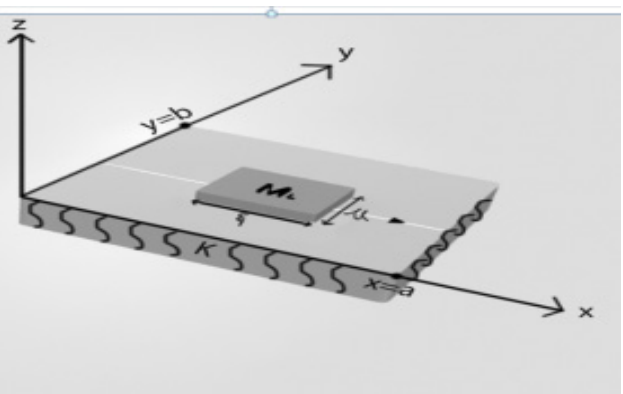

Figure 1: A moving load on the plate supported by Winkler foundation.

\subsection{Initial conditions}

$$
\mathrm{W}(\mathrm{x}, \mathrm{y}, \mathrm{o})=0=\frac{\partial W}{\partial T}(\mathrm{x}, \mathrm{y}, 0)
$$

\subsection{Boundary conditions}

$W(x, y, t)=M_{X}(x, y, t)=\psi_{Y}(x, y, t)=0$, for $x=0$ and $x=a$ $\mathrm{W}(\mathrm{x}, \mathrm{y}, \mathrm{t})=\mathrm{M}_{\mathrm{Y}}(\mathrm{x}, \mathrm{y}, \mathrm{t})=\bigcup_{\mathrm{X}}(\mathrm{x}, \mathrm{y}, \mathrm{t})=0$, for $\mathrm{y}=0$ and $\mathrm{y}=\mathrm{b}$ where $\mathrm{M}_{\mathrm{X}}$ and $\mathrm{M}_{\mathrm{y}}$ are bending moments in the $\mathrm{x}$ - and $\mathrm{y}$-directions respectively, $\psi_{\mathrm{x}}(\mathrm{x}, \mathrm{y}, \mathrm{t})$ and $\psi_{\mathrm{y}}(\mathrm{x}, \mathrm{y}, \mathrm{t})$ are local rotations in the $\mathrm{x}$ - and y-directions respectively. $W(x, y, t)$ is the traverse displacement of the plate at time $t$.

\section{Problem solution}

The set of dynamic equilibrium equations which govern the behaviour of Mindlin plate supported by Winkler foundation and traversed by a partially distributed moving load may be written as $[6,7]$;

$$
\begin{aligned}
\frac{M_{L} B}{A} & {\left[\mathrm{~g}+\frac{\partial^{2} w}{\partial t^{2}}+2 \mathrm{u} \frac{\partial^{2} w}{\partial x \partial t}+\mathrm{u}^{2} \frac{\partial^{2} w}{\partial x^{2}}\right]=} \\
& K^{2} G h\left[-\frac{\partial^{2} w}{\partial x^{2}}+\frac{\partial \Psi_{x}}{\partial x}-\frac{\partial^{2} w}{\partial y^{2}}+\frac{\partial \Psi_{x}}{\partial y}\right]+\rho h \frac{\partial^{2} w}{\partial T^{2}}
\end{aligned}
$$

$$
\begin{gathered}
\mathrm{B} \rho_{\mathrm{L}} \mathrm{h}_{1}^{3}\left[\frac{\partial^{2} \Psi_{x}}{\partial x^{2}}+2 \mathrm{u} \frac{\partial^{2} \Psi_{x}}{\partial x \partial y}+\mathrm{U}^{2} \frac{\partial^{2} \Psi_{x}}{\partial x^{2}}\right]+\frac{\rho h^{3}}{12} \frac{\partial^{2} \Psi_{x}}{\partial t^{2}}=\mathrm{D}\left[\frac{\partial^{2} \Psi_{x}}{\partial x^{2}}+v \frac{\partial^{2} \Psi_{x}}{\partial x \partial y}\right] \\
+\frac{1-v}{2} \mathrm{D}\left[\frac{\partial^{2} \Psi_{y}}{\partial x \partial y}+\frac{\partial^{2} \Psi_{x}}{\partial y^{2}}\right]-\mathrm{K}^{2} \mathrm{Gh}\left(\Psi_{\mathrm{x}}-\frac{\partial w}{\partial x}\right) \\
\mathrm{B} \rho_{\mathrm{L}} \mathrm{h}_{1}^{3}\left[\frac{\partial^{2} \Psi_{y}}{\partial t^{2}}+2 \mathrm{u} \frac{\partial^{2} \Psi_{y}}{\partial y \partial t}+\mathrm{U}^{2} \frac{\partial^{2} \Psi_{y}}{\partial y^{2}}\right]+\frac{\rho h^{3}}{12} \frac{\partial^{2} \Psi_{y}}{\partial t^{2}} \\
=\mathrm{D}\left[\frac{\partial^{2} \Psi_{y}}{\partial y^{2}}+v \frac{\partial^{2} \Psi_{y}}{\partial y \partial x}\right]+\frac{1-\rho}{2} \mathrm{D}\left[\frac{\partial^{2} \Psi_{x}}{\partial x \partial y}+\frac{\partial^{2} \Psi_{y}}{\partial x^{2}}\right]-\mathrm{K}^{2} \mathrm{Gh}\left(\psi_{\mathrm{y}}-\frac{\partial w}{\partial y}\right)
\end{gathered}
$$

$B=B x B y$, such that 


$$
\begin{aligned}
& B x=\left\{\begin{array}{l}
1-\mathrm{H}\left(\mathrm{x}-\xi-\frac{\epsilon}{2}\right), \text { for } 0 \leq t \leq \frac{\epsilon}{\mu} \\
\mathrm{H}\left(\mathrm{x}-\xi+\frac{\epsilon}{2}\right)-\mathrm{H}\left(\mathrm{x}-\xi-\frac{\epsilon}{2}\right), \text { for } \frac{\epsilon}{\mu} \leq \mathrm{t} \leq \frac{L_{x}}{\mu} B x \\
\mathrm{H}\left(\mathrm{x}-\xi+\frac{\epsilon}{2}\right), \text { for } \frac{L_{x}}{\mu} \leq \mathrm{t}<\frac{\left(L_{x}+\epsilon\right)}{\mu} \\
0, \text { for } \frac{L_{x}+\epsilon}{\mu} \leq \mathrm{t}
\end{array}\right. \\
& B_{y}=\left\{\mathrm{H}\left(\mathrm{y}-\mathrm{y}_{1}+\frac{\mu}{2}\right)-\mathrm{H}\left(\mathrm{y}-\mathrm{y}_{1} \frac{\mu}{2}\right)\right\}
\end{aligned}
$$

$H(x)$ is the Heaviside function defined as;

$$
H(x)=\left\{\begin{array}{l}
1, \mathrm{x}>0 \\
0.5, \mathrm{x}=0 \\
0, \mathrm{x}<0
\end{array}\right.
$$

$\mathrm{u}$ is the velocity of a load of rectangular dimension $\epsilon$ and $\mu$ with one of its lines of symmetry moving along $\mathrm{Y}=\mathrm{Y}_{1} ; \mathrm{A}=\mu \in$, the area of the load in contact with the plate. The plate is Lx by Ly in dimension, and $\xi=\mathrm{UT}+\frac{\epsilon}{2}, \mathrm{~h}$ and $\mathrm{h}_{1}$ are thickness of the plate and load respectively. $\rho$ and $\rho_{\mathrm{L}}$ are the densities of the plate and load respectively. $G$ is the modulus of rigidity of the plate. $D$ is the flexural rigidity of the plate defined by $\mathrm{D}=1 / 2 \mathrm{Eh}^{2}\left[\left(1-v^{3}\right)\right]=\mathrm{Gh}^{3} / 6(1-v) . \mathrm{K}^{2}$ is the shear correction factor, $v$ is the poison's ratio of the plate. $G$ is the acceleration due to gravity. $\mathrm{E}$ is the young modulus of Elasticity $M_{L}$ is the mass of the load. $\mathrm{K}$ is the stiffness of the foundation (constant for this case). $\mathrm{M}_{\mathrm{f}}$ is the mass of the foundation.

The bending moments $M x$ and $M y$, the shear deformation $Q x$ and $Q y$ and the twisting moments $M x y$ can be written as [7]:

$$
\begin{gathered}
M x=-\mathrm{D}\left(\frac{\partial \Psi_{x}}{\partial x}+v \frac{\partial \Psi_{y}}{\partial y}\right) \\
M y=-\mathrm{D}\left(\frac{\partial \Psi_{x}}{\partial y}+v \frac{\partial \Psi_{x}}{\partial x}\right) \\
M x y=\frac{-D(1-v)}{2}\left(\frac{\partial \Psi_{x}}{\partial y}+v \frac{\partial \Psi_{y}}{\partial x}\right) \\
Q x=-\mathrm{K}^{2} \mathrm{Gh}\left(\bigcup x-\frac{\partial w}{\partial x}\right) \\
Q y=-K^{2} G h\left(U y-\frac{\partial w}{\partial x}\right)
\end{gathered}
$$

Rewriting equations (1), (2) and (3), and substituting equations (7), (8), (9), (10) and (11) results in 


$$
\begin{gathered}
\frac{\partial Q_{x}}{\partial x}+\frac{\partial Q_{y}}{\partial y}-\rho \mathrm{h} \frac{\partial^{2} W}{\partial t^{2}}+\mathrm{KW}+\mathrm{Mf} \frac{\partial^{2} W}{\partial t^{2}}=\mathrm{P}(\mathrm{x}, \mathrm{y}, \mathrm{t}) \\
Q x-\frac{\partial M_{x}}{\partial x}-\frac{\partial M_{x y}}{\partial y}=\frac{\rho h^{3}}{12} \frac{\partial^{2} \Psi_{x}}{\partial t^{2}}+\frac{\rho_{L} \mathrm{~h}_{1}^{3}}{12}\left(\frac{\partial^{2} \Psi_{x}}{\partial t^{2}}\right) \mathrm{B} \\
Q y-\frac{\partial M_{x}}{\partial y}-\frac{\partial M_{x y}}{\partial x}=\frac{\rho h^{3}}{12} \frac{\partial^{2} \Psi_{y}}{\partial t^{2}}+\frac{\rho_{L} \mathrm{~h}_{1}^{3}}{12}\left(\frac{\partial^{2} \Psi_{y}}{\partial t^{2}}\right) \mathrm{B}
\end{gathered}
$$

where the moving load

$$
\begin{gathered}
P(x, y, t)=\frac{1}{\mu \epsilon}\left[-M_{L} \mathrm{~g}-M_{L} \frac{\partial^{2} W}{\partial t^{2}}\right] \mathrm{B} \\
\frac{d^{2} W}{d t^{2}}=\frac{\partial^{2} W}{\partial t^{2}}+2 \mathrm{u} \frac{\partial^{2} w}{\partial x \partial t}+\mathrm{u}^{2} \frac{\partial^{2} w}{\partial x^{2}} \\
\frac{d^{2} \Psi_{x}}{d t^{2}}=\frac{\partial^{2} \Psi_{x}}{\partial t^{2}}+2 \mathrm{u} \frac{\partial^{2} \Psi x}{\partial x \partial t}+\mathrm{u}^{2} \frac{\partial^{2} \Psi x}{\partial x^{2}} \\
\frac{d^{2} \Psi_{y}}{d t^{2}}=\frac{\partial^{2} \Psi_{y}}{\partial t^{2}}+2 \mathrm{u} \frac{\partial^{2} \Psi y}{\partial y \partial t}+\mathrm{u}^{2} \frac{\partial^{2} \Psi y}{\partial y^{2}}
\end{gathered}
$$

From equation (10)

$$
\frac{\partial w}{\partial x}=\bigcup_{x}-\frac{Q_{x}}{\alpha G h}
$$

Substituting (10) into (16) we have

$$
\frac{d^{2} W}{d t^{2}}=\frac{\partial^{2} W}{\partial t^{2}}+\mathrm{u} \frac{\partial^{2} w}{\partial x \partial t}+\mathrm{u}\left\{\frac{\partial \psi x}{\partial t}+\mathrm{u} \frac{\partial \psi x}{\partial x}\right\}-\frac{Q_{x}}{\alpha G h}\left\{\frac{\partial Q x}{\partial x}+u \frac{\partial Q x}{\partial x}\right\}
$$

where $\alpha=-k^{2}$.

Solving for $\frac{\partial \psi x}{\partial x}$ in equations (7) and (8) we have

$$
\frac{\partial \psi x}{\partial x}=\frac{M_{x-v M_{y}}}{D\left(v^{2}-1\right)}
$$

Substituting (21) into (20) yields

$$
\frac{d^{2} W}{d t^{2}}=\frac{\partial^{2} W}{\partial t^{2}}+\mathrm{u} \frac{\partial^{2} w}{\partial x \partial t}+\mathrm{u}\left\{\frac{\partial \psi x}{\partial t}+\mathrm{u} \frac{\left(M_{x}-v M_{y}\right)}{D\left(v^{2}-1\right)}\right\}-\frac{u}{\alpha G h}\left\{\frac{\partial Q x}{\partial t}+u \frac{\partial Q x}{\partial x}\right\}
$$

Similarly, by virtue of (21), we have,

$$
\begin{aligned}
\frac{d^{2} \Psi_{x}}{d t^{2}}= & \frac{\partial^{2} \Psi_{x}}{\partial t^{2}}+\mathrm{u} \frac{\partial^{2} \Psi x}{\partial x \partial t}+u \frac{\partial}{\partial t}\left(\frac{\partial \Psi x}{\partial x}\right)+u^{2} \frac{\partial}{\partial x}\left(\frac{\partial \Psi_{x}}{\partial x}\right)=\frac{\partial^{2} \Psi_{x}}{\partial t^{2}} \\
& +\mathrm{u} \frac{\partial^{2} \Psi x}{\partial x \partial t}+\mathrm{u} \frac{\partial}{\partial t} \frac{\left(M_{x}-v M_{y}\right)}{D\left(v^{2}-1\right)}+u^{2} \frac{\partial}{\partial x} \frac{\left(M_{x}-v M_{y}\right)}{D\left(v^{2}-1\right)}
\end{aligned}
$$


Therefore,

$$
\frac{d^{2} \Psi_{x}}{d t^{2}}=\frac{\partial^{2} \Psi_{x}}{\partial t^{2}}+\mathrm{u} \frac{\partial^{2} \Psi x}{\partial x \partial t}+\frac{u}{D\left(v^{2}-1\right)}\left\{\frac{\partial M_{x}}{\partial t}+\mathrm{u} \frac{\partial M_{x}}{\partial t}+\mathrm{u} \frac{\partial M_{x}}{\partial}\right\} \frac{u v}{D\left(v^{2}-1\right)}\left\{\frac{\partial M_{y}}{\partial t}+\mathrm{u} \frac{\partial M_{y}}{\partial x}\right\}
$$

Similarly equation $(3.18)$ reduces to

$$
\frac{d^{2} \Psi_{y}}{d t^{2}}=\frac{\partial^{2} \Psi_{y}}{\partial t^{2}}+\mathrm{u} \frac{\partial^{2} \Psi y}{\partial y \partial t}+\frac{U}{D\left(v^{2}-1\right)}\left\{\frac{\partial M_{y}}{\partial t}+\mathrm{u} \frac{\partial M_{y}}{\partial T}+\mathrm{u} \frac{\partial M_{y}}{\partial y}\right\}-\frac{U v}{D\left(v^{2}-1\right)}\left\{\frac{\partial M_{x}}{\partial t}+\mathrm{u} \frac{\partial M_{x}}{\partial y}\right\}
$$

By virtue of (16), the expression on the left hand side of equation (1) reduces to

$$
-\frac{1}{\mu \in}\left[-M_{L} \mathrm{~g}-M_{L} \frac{d^{2} W}{d t^{2}}\right] \mathrm{B}=P(x, y, t)
$$

where $P(x, y, t)$ is the moving load

Now equation (1), (2), and (3) can be written as

$$
\begin{aligned}
& -\frac{1}{\mu \epsilon}\left[-M_{L} \mathrm{~g}-M_{L} \frac{d^{2} W}{d t^{2}}\right] \mathrm{B}=\mathrm{K}^{2} \mathrm{Gh}\left[-\frac{\partial^{2} W}{\partial x^{2}}+\frac{\partial \Psi x}{\partial x}-\frac{\partial^{2} W}{\partial y^{2}}+\frac{\partial \psi y}{\partial y}\right]+\rho \mathrm{h} \frac{\partial^{2} W}{\partial t^{2}} \\
& \quad=\mathrm{KW}-\mathrm{M}_{\mathrm{f}} \frac{\partial^{2} W}{\partial t^{2}}
\end{aligned}
$$

$$
\begin{aligned}
& \frac{\mathrm{B} \rho_{L} \mathrm{~h}_{1}^{3}}{12}\left(\frac{d^{2} \Psi_{x}}{d t^{2}}\right)+\frac{\rho h^{3}}{12} \frac{\partial^{2} \Psi_{x}}{\partial T^{2}}=\mathrm{D} \frac{\partial}{\partial x}\left[\frac{\partial \Psi x}{\partial x}+v \frac{\partial \Psi_{y}}{\partial y}\right]+\frac{D(1-v)}{2} \frac{\partial}{\partial y}\left[\frac{\partial \psi x}{\partial y}+\frac{\partial \Psi_{y}}{\partial x}\right] \\
& -\mathrm{K}^{2} \mathrm{Gh}\left(\psi_{\mathrm{x}}-\frac{\partial w}{\partial x}\right)
\end{aligned}
$$

$$
\begin{aligned}
& \frac{\mathrm{B} \rho_{L} \mathrm{~h}_{1}^{3}}{12}\left(\frac{d^{2} \Psi_{y}}{d t^{2}}\right)+\frac{\rho h^{3}}{12} \frac{\partial^{2} \psi_{y}}{\partial t^{2}}=\mathrm{D} \frac{\partial}{\partial y}\left[\frac{\partial \Psi y}{\partial y}+v \frac{\partial \Psi_{x}}{\partial x}\right]+\frac{D(1-v)}{2} \frac{\partial}{\partial x}\left[\frac{\partial \psi x}{\partial y}+\frac{\partial \Psi_{y}}{\partial x}\right] \\
& -\mathrm{K} 2 \mathrm{Gh}\left(\psi_{\mathrm{x}}-\frac{\partial w}{\partial y}\right)
\end{aligned}
$$

Moreover, note that [6]

$$
\begin{gathered}
\mathrm{M}_{\mathrm{x}}=-\mathrm{D}\left(\frac{\partial \psi x}{\partial x}+v \frac{\partial \Psi_{y}}{\partial y}\right) \\
\mathrm{M}_{\mathrm{y}}=-\mathrm{D}\left(\frac{\partial \psi x}{\partial y}+v \frac{\partial \Psi_{x}}{\partial x}\right) \\
\mathrm{M}_{\mathrm{xy}}=\frac{-D(1-v)}{2}\left(\frac{\partial \psi x}{\partial y}+\frac{\partial \psi_{y}}{\partial x}\right) \\
\mathrm{Q}_{\mathrm{x}}=-\mathrm{K}^{2} \mathrm{Gh}\left(\Psi_{\mathrm{x}}-\frac{\partial w}{\partial x}\right) \\
\mathrm{Q}_{\mathrm{y}}=-\mathrm{K}^{2} \mathrm{Gh}\left(\psi_{\mathrm{y}}-\frac{\partial w}{\partial y}\right)
\end{gathered}
$$


Substituting equations (30), (31), (32), (33) and (34) into (27), (28) and (29) yield;

$$
\begin{aligned}
\frac{\partial Q_{x}}{\partial x} & +\frac{\partial Q_{y}}{\partial y}+\mathrm{KW}+\mathrm{Mf} \frac{\partial D t}{\partial t}+\frac{M_{L}}{A}\left[\mathrm{~g}+\frac{\partial D T}{\partial T}+\mathrm{U} \frac{\partial D t}{\partial t}+\mathrm{U}\left\{U \mathrm{x}, \mathrm{t}+\frac{U}{D\left(v^{2}-1\right)} \mathrm{Mx}\right.\right. \\
& \left.\left.-\frac{U_{v} M_{y}}{D\left(v^{2}-1\right)}\right\}-\frac{\mathrm{U}}{\ltimes G h}\left\{\frac{\partial Q_{x}}{\partial T}+\mathrm{U} \frac{\partial Q t}{\partial x}\right\}\right] \mathrm{B}=\rho \mathrm{h} \frac{\partial D T}{\partial T} \\
\mathrm{Q}_{\mathrm{x}} & \frac{\partial M_{x}}{\partial x} \frac{\partial M_{x y}}{\partial y}=\frac{\rho h^{3}}{12} \frac{\partial \cdot \Psi_{x, t}}{\partial t}+\rho \mathrm{Lh}_{1}^{3}\left[\frac{\partial \cdot \Psi_{x, t}}{\partial t}+\mathrm{U} \frac{\partial \cdot \psi_{x, t}}{\partial y}+\frac{U}{D\left(v^{2}-1\right)}\left\{\frac{\partial M_{x}}{\partial t} \mathrm{U} \frac{\partial M_{x}}{\partial x}\right\}\right. \\
& \left.-\frac{U_{v}}{D\left(v^{2}-1\right)}\left\{\frac{\partial M_{y}}{\partial t} \mathrm{U} \frac{\partial M_{y}}{\partial x}\right\}\right] \mathrm{B} \\
\mathrm{Q}_{\mathrm{y}} & -\frac{\partial M_{x y}}{\partial x}-\frac{\partial M_{y}}{\partial y}=\frac{\rho h^{3}}{12} \frac{\partial \psi \Psi_{x, t}}{\partial t}+\frac{\rho_{\mathrm{L}} \mathrm{h}_{1}^{3}}{12}\left[\frac{\partial \Psi_{\psi x, t}}{\partial t}+\mathrm{U} \frac{\partial \psi \Psi_{x, t}}{\partial y}+\frac{U}{D\left(v^{2}-1\right)}\left\{\frac{\partial M_{y}}{\partial t}\right.\right. \\
& \left.\left.+\mathrm{U} \frac{\partial M_{y}}{\partial x}\right\}-\frac{U_{v}}{D\left(v^{2}-1\right)}\left\{\frac{\partial M_{y}}{\partial t}+\mathrm{U} \frac{\partial M_{x}}{\partial y}\right\}\right] \mathrm{B}
\end{aligned}
$$

where $\left(\mathrm{M}_{\mathrm{f}}-\rho h\right)=\mathrm{M}, \quad \mathrm{D}_{\mathrm{t}}=\frac{\partial \mathrm{W}}{\partial t}$.

Equation (35), (36) and (37) can be written as first order partial differential equations as follows:

$$
\begin{aligned}
& \frac{d Q_{x}}{d x}+\frac{d Q_{y}}{d y}+\mathrm{KW}+\quad \mathrm{M}_{\mathrm{f}} \frac{\partial D t}{\partial t}+\quad \frac{M_{L}}{A}\left[\mathrm{~g}+\frac{\partial D t}{\partial t}+u \frac{\partial D t}{\partial t}+\mathrm{u}\left\{\bigcup \mathrm{x}, \mathrm{t}+\frac{U}{D\left(v^{2}-1\right)} \mathrm{M}_{\mathrm{x}}\right.\right. \\
& \left.\left.-\frac{U_{v} M_{y}}{D\left(v^{2}-1\right)}\right\}-\frac{\mathrm{U}}{\propto G h}\left\{\frac{\partial Q_{x}}{\partial t}+u \frac{\partial Q x}{\partial x}\right\}\right] \mathrm{B}=\rho \mathrm{h} \frac{\partial D T}{\partial T} \\
& \mathrm{Q}_{\mathrm{x}}-\frac{\partial M_{x}}{\partial x}-\frac{\partial M_{x y}}{\partial y}=\frac{\rho h^{3}}{12} \frac{\partial \Psi_{x, t}}{\partial t}+\frac{\rho_{\mathrm{L}} \mathrm{h}_{1}^{3}}{12}\left[\frac{\partial \Psi_{x, t}}{\partial t}+\mathrm{u} \frac{\partial \Psi_{x, t}}{\partial y}+\frac{U}{D\left(v^{2}-1\right)}\left\{\frac{\partial M_{x}}{\partial t}+\mathrm{u} \frac{\partial M_{x}}{\partial x}\right\}\right. \\
& \left.-\frac{U_{v}}{D\left(v^{2}-1\right)}\left\{\frac{\partial M_{y}}{\partial t}+\mathrm{u} \frac{\partial M_{y}}{\partial x}\right\}\right] \mathrm{B} \\
& \mathrm{Q}_{\mathrm{y}^{-}} \frac{\partial M_{x y}}{\partial x}-\frac{d M_{y}}{\partial y}=\frac{\rho h^{3}}{12} \frac{\partial \Psi_{y, t}}{\partial t}+\frac{\rho_{\mathrm{L}} \mathrm{h}_{1}^{3}}{12}\left[\frac{\partial \Psi_{y, t}}{\partial t}+\mathrm{u} \frac{\partial \Psi_{y, t}}{\partial x}+\frac{U}{D\left(v^{2}-1\right)}\left\{\frac{\partial M_{y}}{\partial t}+\mathrm{u} \frac{\partial M_{y}}{\partial y}\right\}\right. \\
& \left.-\frac{U_{v}}{D\left(v^{2}-1\right)}\left\{\frac{\partial M_{x}}{\partial t}+\mathrm{u} \frac{\partial M_{x}}{\partial y}\right\}\right] \mathrm{B}
\end{aligned}
$$

where $\psi_{x, t}=\frac{\partial \psi_{x}}{\partial t}$ and $\psi_{y, t}=\frac{\partial \psi_{y}}{\partial t}$.

Differentiating equations (30), (31), (32), (33), and (34) with respect to $t$ yields respectively:

$$
\begin{gathered}
\frac{\partial M_{x}}{\partial t}=-\mathrm{D} \frac{\partial \Psi_{x, t}}{\partial x}-\mathrm{D} v \frac{\partial \Psi_{y, t}}{\partial y} \\
\frac{\partial M_{y}}{\partial t}=-\mathrm{D} \frac{\partial \Psi_{y, t}}{\partial y}-\mathrm{D} v \frac{\partial \Psi_{x, t}}{\partial x} \\
\frac{\partial M_{x y}}{\partial t}=\frac{-D(1-v)}{2}\left\{\frac{\partial \Psi_{x, t}}{\partial y}+\frac{\partial \Psi_{y, t}}{\partial x}\right\}
\end{gathered}
$$




$$
\begin{aligned}
& \frac{\partial Q_{x}}{\partial t}=\alpha \mathrm{hG}\left(\Psi_{x, t^{-}} \frac{\partial^{2} W}{\partial x \partial t}\right) \\
& \frac{\partial Q_{y}}{\partial t}=\alpha \mathrm{hG}\left(\Psi_{y, t^{-}} \frac{\partial^{2} W}{\partial y \partial t}\right)
\end{aligned}
$$

The set of first order partial differential equations (38)-(45) with

$$
D_{t}=\frac{\partial W}{\partial t}
$$

are the simplified partial differential equations to be solved for the following nine dependent variables: $\mathrm{Q}_{\mathrm{x}}, \mathrm{Q}_{\mathrm{y}}, \mathrm{M}_{\mathrm{x}}, \mathrm{M}_{\mathrm{y}}, \mathrm{M}_{\mathrm{xy}}, \psi_{\mathrm{x}, \mathrm{t}}, \psi_{\mathrm{y}, \mathrm{t}}, \mathrm{D}_{\mathrm{t}}$ and W. A numerical procedure, finite difference method, can be used to solve the system of equations (38)-(46). [6]

Rearranging them in matrix form results in:

$$
\begin{gathered}
\mathrm{H}_{\mathrm{i}, \mathrm{j}+1} \mathrm{~S}_{\mathrm{i}, \mathrm{j}+1}+\mathrm{I}_{\mathrm{i}+1, \mathrm{j}+\mathrm{i}} \mathrm{S}^{\prime}{ }_{\mathrm{i}+1, \mathrm{j}+1}=-\mathrm{G}_{\mathrm{i}, \mathrm{j}} \mathrm{S}_{\mathrm{I}, \mathrm{j}}-\mathrm{J}_{\mathrm{i}+1, \mathrm{j}} \mathrm{S}_{\mathrm{i}+1, \mathrm{j}}+\mathrm{L}_{\mathrm{k}} \\
\mathrm{i}=1,2,3, \ldots, \mathrm{N}-1 ; \mathrm{j}=1,2,3, \ldots \mathrm{M}-1
\end{gathered}
$$

where $\mathrm{N}$ and $\mathrm{M}$ are the number of the nodal points along $\mathrm{X}$ and $\mathrm{Y}$ axes respectively.

$$
\mathrm{L}_{\mathrm{k}}=\mathrm{K}_{\mathrm{i}, \mathrm{j}} \mathrm{S}_{\mathrm{i}, \mathrm{j}}+\mathrm{L}_{\mathrm{i}, \mathrm{j}+\mathrm{i},} \mathrm{S}_{\mathrm{i}, \mathrm{j}+1} \mathrm{M}_{\mathrm{i}+1} \mathrm{~S}_{\mathrm{i}+1, \mathrm{j}}+\mathrm{N}_{\mathrm{i}+1, \mathrm{j}+1} \mathrm{~S}_{\mathrm{i}+1, \mathrm{j}+1}+\mathrm{P}_{1}
$$

Each term in equations (47) and (48) is a $9 \times 9$ matrix.

\section{The shear, rotatory and Kirchhoff railway bridges (plates) resting on a Winkler foundation}

In order to compare the effects of shear deformation and rotatory inertia on the deflection of the railway track under a moving railway vehicle (load) supported by a sub-grade, the following types of plates are considered; the share plate (no rotatory inertia effect.), the rotatory plate (no shear deformation effect) and Kirchhoff plate (non-Mindlin plate).

\section{Results discussion}

The numerical calculations were carried out for a simply supported rectangular plate (railway bridge) resting on a Winkler foundation and subjected to a moving railway vehicle (load.). Damping effect was neglected. For a specific value of foundation stiffness $K$ and contact area $\left(A_{r}\right)$, deflection of the Mindlin plate is calculated and plotted (in figure 2) as a function of time. It is observed that Mindlin plate has highest maximum amplitude when compared with nonMindlin plate, plate without rotating effect and plate without shear deformation effect. The plate without shear deformation effect has the least. In figure 3 , the 
deflection of the Mindlin plate resting on a Winker foundation due to the moving partially distributed load is plotted as a function of time for $\mathrm{K}=100$ and various values of contact areas $\left(A_{r}\right)$.Clearly, from the figure, the response maximum amplitude of the Mindlin plate decreases with an increase in the contact area (Ar) of the moving load, for a fixed value of velocity $u$. The effect of the Winkler

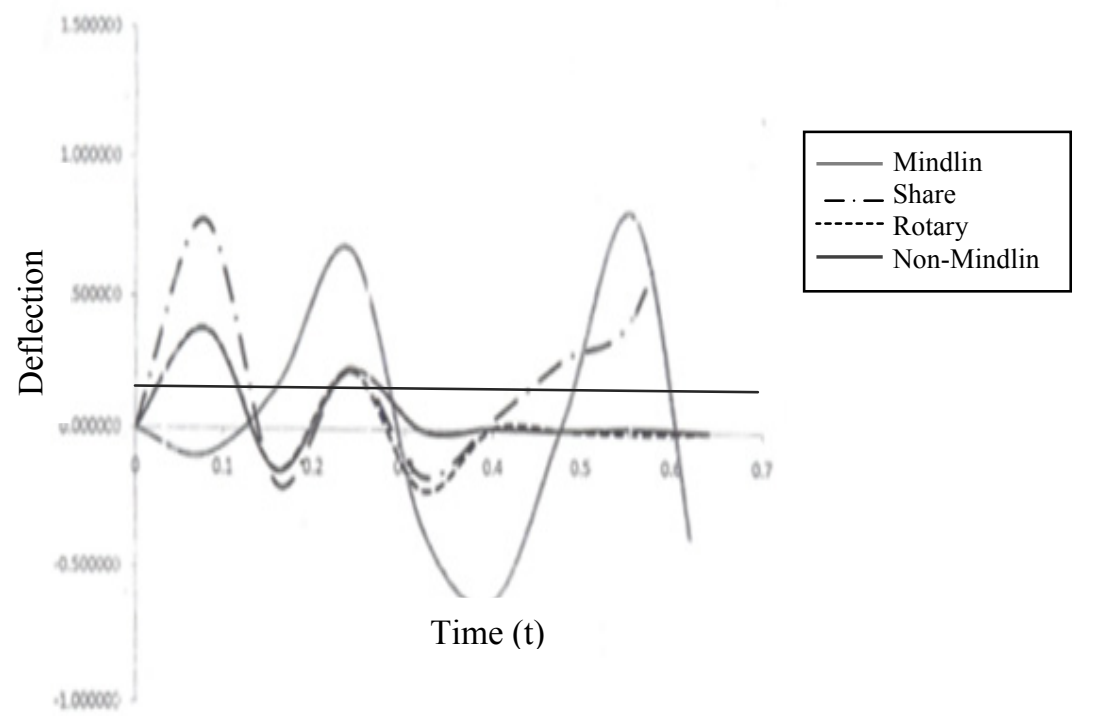

Figure 2: Deflection of different plates at $\mathrm{K}=100, \mathrm{Ar}=0.5, \mathrm{u}=1.5$ and various values of time.

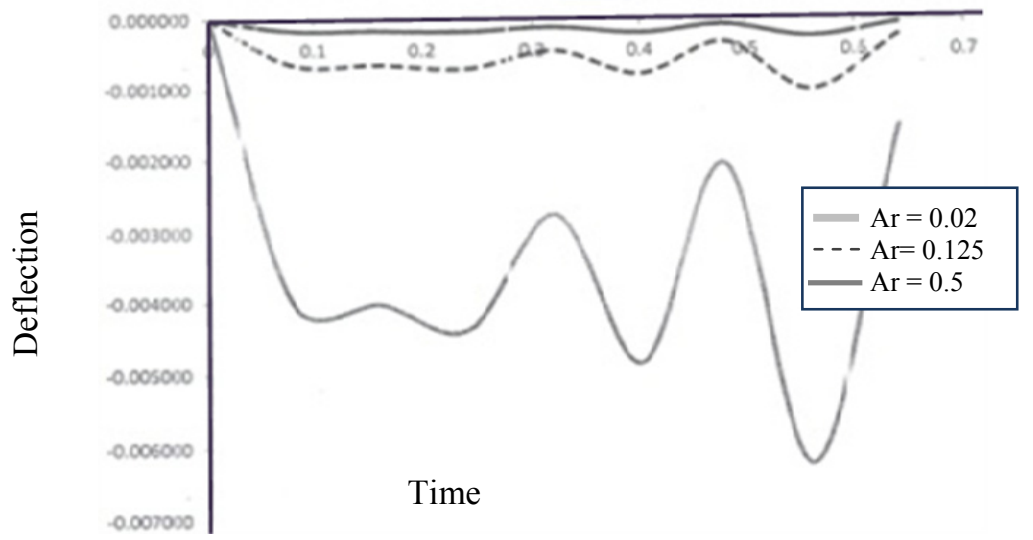

Figure 3: Deflection of the plate at $\mathrm{K}=100$ and various value of $\mathrm{Ar}$ and time. 
foundation on the deflection of the Mindlin plate is shown in figure 4. Evidently, it is noted that the response maximum amplitude decreases as the foundation stiffness $\mathrm{K}$ increases for fixed values of velocity $\mathrm{u}$ and contact area Ar. Figure 5 shows the deflection of the plate for various values of velocity $u$. It can also be seen that the response maximum amplitude of the plate decreases as velocity decreases.

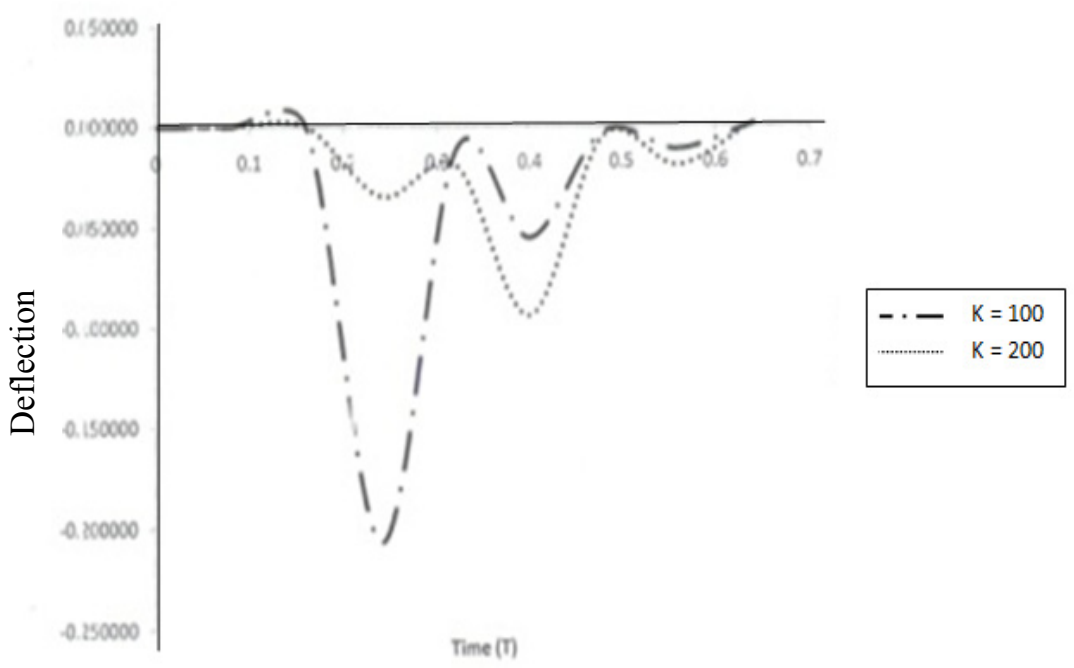

Figure 4: Comparing the effect of $\mathrm{K}=100$ with $\mathrm{K}=200$ on the deflection of Mindlin plate resting on Winkler foundation when velocity $\mathrm{u}=5.5$.

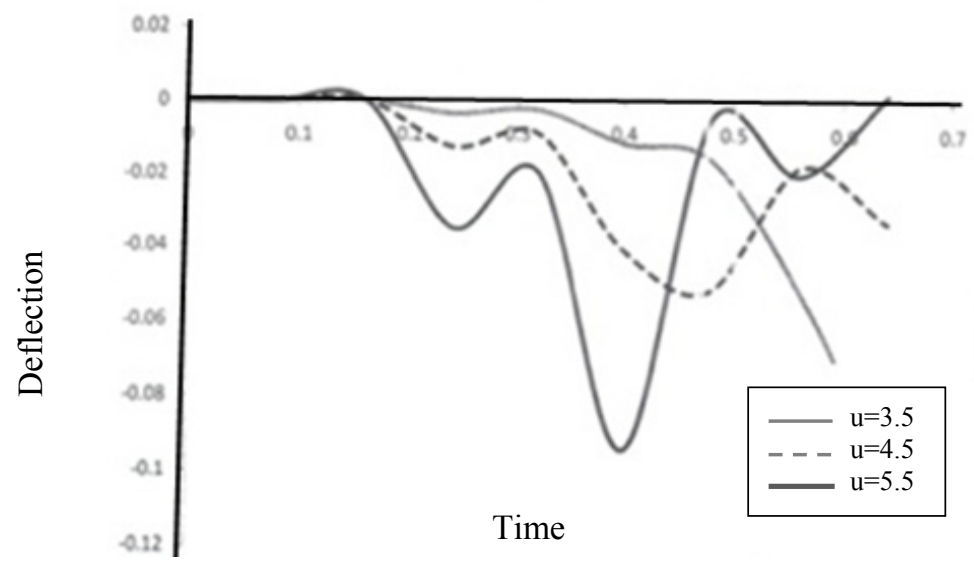

Figure 5: Deflection of Mindlin plate at $\mathrm{K}=200$ and different values of velocity and time. 


\section{Conclusion}

The structure of interest was a Mindlin rectangular elastic plate (railway track) on Winkler elastic foundation, under the influence of a uniform partially distributed moving load (railway vehicle). The problem was to determine the dynamic response of the whole system. Finite difference technique was adopted in solving the resulting first order coupled partial differential equations obtained from governing equations for the simply supported Mindlin plate. The study has contributed to scientific knowledge by showing that the elastic subgrade on which the Mindlin plate rests has a significance effect on the dynamic response of the plate to a partially distributed load. The effect of rotating inertia and shear deformation on the dynamic response of the Mindlin plate (railway track) to the moving railway vehicle (load) gives more realistic results for practical application, especially when such plate is considered to rest on a foundation.

\section{References}

[1] Rossi Thomas D. Chladin's Law for Vibrating Plates. American Journal of Physics, 1982; 50:3.

[2] Fryba Ladislaw. Vibration of Solids and Structures under Moving Loads. Noordloff International Publishing Groningen, the Netherlands, 1972.

[3] Civalek O. Large Deflection Static and Dynamic Analysis of Thin Circular Plates Resting On Two Parameter Elastic Foundation HDQ/FO Couple Methodology Approaches. International Journal of Computational

[3] Mechanics, 2005 2(2): 271-291.

[4] Civalek O. and Yavas A. Large Deflection Static Analysis of Rectangular Plates on Two Parameter Elastic Foundation. International Journal of Science and Technology 2006; 1:43-50.

[5] Dowell E. H. Dynamic Analysis of an Elastic Plate on a Thin Elastic Foundation. Journal of Sound and Vibration. 1974; 35: 343-360.

[6] Gbadeyan J. A. and Dada M. S. Dynamic Response of a Mindlin Elastic Rectangular Plate under a Distributed Moving Mass. International Journal of Mechanical Science. 2006; 48: 323-340.

[7] Gbedeyan J. A and Dada M. S. The Dynamic Response of Plateson Pasternak Foundation to Distributed Moving Load, Journal of the Nigerian Association of Mathematical Physics. 2001; 5: 185-200.

[8] Young J. A. and Appa Rao. The Lateral Dynamics of a Rail Transit Vehicle A Comparison of Experimental and Theoretical Results. ASME Winter Annual Meeting in San Francisco, 1978.

[9] Gerg V. K and Dukkipati R.V Dynamics of Railway Vehicle Systems. Academic Press New York, 1984.

[10] Mindlin R. D. Influence of Rotatory To Inertia and Shear on Flexural Motions of Isotropic Elastic Plates. Journal of Applied Mechanics 1957: 18. 